\title{
Hidden Curriculum Design of Traditional Art Community Rampak Kendang
}

\author{
Fery Setyaningrum ${ }^{\mathrm{a}, 1,{ }^{*}}$,Heni Siswantari ${ }^{\mathrm{b}, 2}$, Lono Lastoro Simatupang ${ }^{\mathrm{c}, 3}$, Paramitha Dyah Fitriasari ${ }^{\mathrm{d}, 4}$ \\ a Ahmad Dahlan University, Ki Ageng pemanahan Street, Yogyakarta 55162, Indonesia

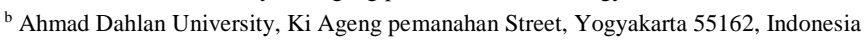 \\ ${ }^{\mathrm{c}}$ Gadjah Mada University, Tehnika Utara Street, Yogyakarta 55281, Indonesia \\ d. Gadjah Mada University, Tehnika Utara Street, Yogyakarta 55281, Indonesia \\ ${ }^{1}$ fery.setyaningrum@pgsd.uad.ac.id; ${ }^{2}$ heni.siswantari@pgsd.uad.ac.id; \\ ${ }^{3}$ lono_simatupang@yahoo.com ; ${ }^{4}$ paramitha_df@ugm.ac.id \\ * corresponding author
}

ARTICLE INFO

Article history

Received 2019-11-15

Revised 2019-11-17

Accepted 2019-12-09

Keywords

Hidden Curriculum Design

Rampak Kendang

Traditional Art Community

\section{ABSTRACT}

The hidden curriculum is defined as the hidden curriculum imposed on system-specific education (both formal and non-formal. Discussion of the curriculum in Indonesia is interesting is related to the hidden curriculum in non-formal education is the Rampak Kendang community. The characteristics of the population and the different teaching processes from other cities can form different and exciting outputs to be studied. The purpose of this study is to find and describe curriculum designs in the traditional art community of Rampak Kendang in Patimuan Cilacap, Indonesia. This study used a qualitative descriptive method. Data collection techniques using observation, interviews, and documentation. Participation observation with the subject of scrutiny and discussions with the Rampak Kendang community, Patimuan community, the Department of Education in Patimuan. Analysis of the data used data reduction, data presentation, and data verification. The results of this study are the discovery of curriculum design in the form of a hidden curriculum prototype of the Patimuan Rampak Kendang. In the prototype, there is an art learning process through agents as trainers (community leaders) equipped with Patimuan (Sundanese Javanese) art and arts (engineering \& creativity). This is then taught through training (learning processes) to other members of the Rampak Kendang community, in the long learning process influenced by the consensus (mutual agreement), and the support system form society. So that six more slices are found in the form of P, T, I (Process, Textual, Internal), K, P, I (contextual, Internal Process), T, P, E (Textual, Process, External), K, H, E (contextual, result, external), T, H, E (Textual, Result, External), K, I, H (Contextual, Internal, Result). These processes resulted in the discovery of the development of multiple intelligence members, namely kinesthetic, musical, visual-spatial, verbal, interpersonal, and intrapersonal.

\section{Introduction}

The curriculum in Indonesia is always developing and always changing according to the times. Changes to a good curriculum should be periodic and have distance and time so that the results obtained can be maximized. The curriculum in Indonesia itself has changed since 1947 until now in 2019. Some of them are the 1994 curriculum, KBK, KTSP to Curriculum 13 (k-13) in 2019. K-13 itself now refers to the goals of education that lead to character education. The learning process is equipped with a variety of activities or activities to form a student's character outside the written 
curriculum, which is then referred to as the hidden curriculum. Research written [1] related to hidden curriculum indicates to student learning that takes place at school as a result of the actions of school personnel, parents, students, and other community agents so that the hidden curriculum is antithetic to the formal curriculum. Based on the description above to get the key to success in learning is not solely based on the syllabus (structured) in school. However, a hidden curriculum can also help solve problems in the school (classroom) through the dynamics in the school. This becomes interesting when there is a hidden curriculum in a curriculum application, informal education. Related to the view above, the hidden curriculum is not only applied in formal education but also uses in the community art community (not official). An editorial discusses a significant relationship between population, curriculum, and learning in which all three are interrelated and have problems that affect one another [2]. This makes researchers interested in an object of research, namely the community art community, namely Rampak Kendang. Discussion related to the hidden curriculum in traditional art community Rampak Kendang is critical considering there is no discourse related to the practice of teaching traditional arts (non-formal art community) within the hidden curriculum framework. Besides, there are salient differences in terms of the art teaching process therein, which can produce output that is different from other traditional art communities.

Rampak Kendang is one of the traditional arts communities that developed in the Patimuan region of the Cilacap Regency. Culture and art were born from a background of love for the arts of music and various kinds of arts and culture in the region. Geographically, Patimuan sub-district borders directly between Central Java and West Java. This condition can form a different characteristic of society and culture and art as a characteristic of the area. The existence of "Rampak Kendang Art" is increasingly known by various kinds of the wider community. Based on preobservations in the area, if there were more than two types of Rampak Kendang communities in Patimuan, Cilacap Regency, as one of the proofs of the existence of these communities was the appearance of the Rampak Kendang art in the celebration of the opening of Popdaseni in Cilacap, the Kendang Rampak dance performed by the teachers from UPT Patimuan Subdistrict enlivened the opening of the regional student sports week and the national art competition festival of the Cilacap Regency level in 2017, which was held on Friday 21 April 2017 in Pertamina Field on Jalan Mt Haryono, Cilacap Regency [3].

The existence of the Rampak Kendang art community until now has broken the understanding [4] that considers the traditional performance system is no longer appropriate to use and is not following current developments. The existing performance system in the conventional art community of Rampak Kendang is still running well. Even now, it is increasingly recognized and included in one of the learning materials in elementary schools. Although the intended object is different from the results of Nel's research, the two objects have the same "traditional" nature between business performance vs. an art community. In reality, the art of the Rampak Kendang art community is increasingly developing with the community and stakeholders who contribute to preserving the art community. A community-based art curriculum or within society will be formed if facilitated and supported by social, political, economic, technological, and educational [5]. This makes the existence of the Rampak kendang art community increasingly alive with a system that is supported by the surrounding community. The finding also strengthens this that a performance such as the movements, formulations, and manifestations arising from the performance art itself can influence curricular practices (curriculum) dynamically [6]. These findings clearly show the connection between performance art and a system, curriculum, and learning of skill in the community. Departing from the above problems, the hidden curriculum design in the Rampak Kendang art community must be depicted in a prototype to be used as an example in improving the quality of other art communities both in their input, process, and output. The significance and contribution of the results of this study are also able to describe one form of non-formal learning that is identical to the curriculum in school, that is character so that it can be synergy in learning art in the classroom.

\section{Method}

The design of this study was a qualitative study using an ethnographic approach. The study was conducted intensively for two years and participated in all community activities from preparation, training process to performing arts. The data collection method uses observation, interviews, and document studies involving community leaders (trainers), dancer leaders, community members (musicians \& dancers), Patimuan communities, and elementary school teachers in Patimuan, as well 
as elementary school students. For the study of the document, the most important is to examine the data of documents that existed from the past until now (2019) to find out the various relationships with the researcher's problems. The validity of the data is to use source triangulation techniques and triangulation techniques. Triangulation of sources in the field was taken from the results of researchers' interviews with musicians and dancers, members of the arts community, Patimuan community, elementary school teachers, elementary school students (who are members of the Rampak Kendang art community). Source from a variety of researcher's sources, researchers will link each source to be concluded [7]. Analysis of the data used data reduction, data presentation, and verification of data obtained in the form of documents and research notes in the form of a long description needs to be reduced. Data reduction is part of the analysis which aims to emphasize, shorten, focus, and discard what is not crucial so that the conclusions can be drawn valid, then, the presentation of data entirely and honestly, obtained in observations, interviews, and documentation that have been carried out. Furthermore, the data are analyzed between categories and existing problems so that the presentation can be more transparent and systematic. Verification is the final step in data analysis after data reduction and performance. The data presentation is interpreted in a routine discussion. Data that is verified in this study will ultimately be able to answer the research problems that have been formulated previously. Data analysis techniques used in this study also refer to data analysis [8].

\section{Results and Discussion}

Education is a way to develop and build the quality of human resources. One of the knowledge that must be fulfilled in Indonesia is formal education (in schools) that applies the education curriculum - referring to the two major theories of the curriculum there are three main contributions in the body of knowledge about the curriculum. The first concept, stated by Albert refers to the syllabus only as an educational program consisting of three critical elements, such as learning, activities, and guidance [9]. The second concept given by Taba is seen in the curriculum as a function of public schools, there is a list of three curriculum functions, namely to preserve and transmit cultural heritage, function as an instrument for cultural transformation, and work as a means for individual development [10]. In line with the above view, it can be concluded that the curriculum itself occurs with a combination of elements of the learning process with the direction or guidance of each session, besides the curriculum is also closely related to cultural heritage according to Taba above, with its preservation in the form of transferring culture to the next generation, and as a tool to develop everyone. So the curriculum in this context, when associated with observational data on the art of Rampak Kendang in Patimuan Indonesia, is in line with the curriculum that is indirectly composed of the community. In addition to the learning process and guidance or direction from the chairman/trainer as an agent in education to transfer the art, the community agent named Riswanto is given to all community members from dancers to musicians. Figure 1 shows the training activities of members of the Rampak Kendang community consisting of several generations as a form of inheritance. This is consistent with the concept of curriculum content in the way of cultural heritage, which is closely related to the process. Thus, the process of cultural inheritance is also called socialization.

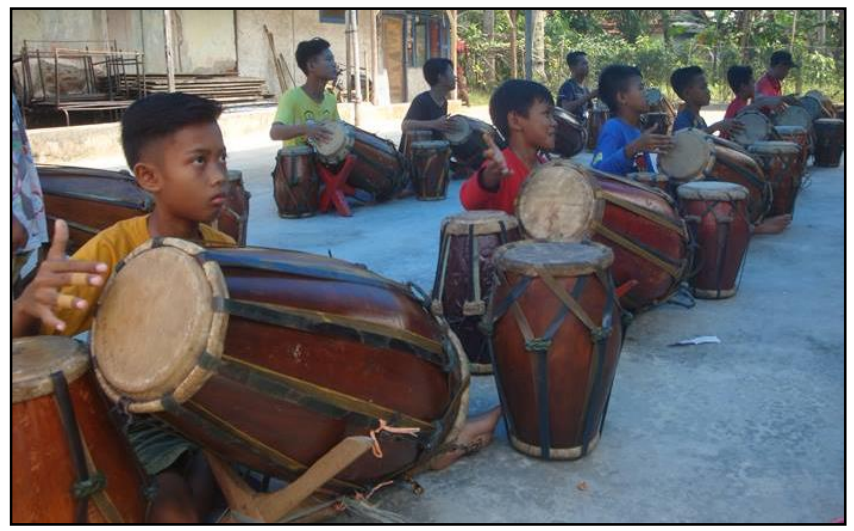

Fig. 1. The atmosphere of the art of Rampak Kendang training in Patimuan Indonesia, the practice was led by the chairman of the community named Riswanto (Documentation: Eva, 2019) 
The method of cultural legacy is carried out by the community throughout life from birth until the end of life. The purpose of cultural inheritance is to shape the attitudes and behavior of citizens following the culture of the community. In the process of succession from one generation to the next, there is a process of adjustment and refinement of learning that is inherited following the times and the progress of society. There is always a cultural dynamic that is always moving forward so that the culture changes and develops not the same as the original culture [11]. This is in line with the Rampak Kendang community performing cultural inheritance (music and dance art) that shapes the character and behavior of the members of the city. The success of a process of succession is also inseparable from the existence of creativity in it. The development of Persian traditional music that is getting better through creativity in music composition by involving digital work systems, namely deep neural networks [12]. Inheritance is not always in the form of art material only, but also through the formation of management in it as well as the pattern of inheritance of fine arts in Australia which applies the concept of rock art so that it becomes a reminder to the public about cultural heritage [13]. This kind of pattern is also carried out by the Rampak Kendang community through performances in various fields, both society and the world of education. In this way, the inheritance of Rampak Kendang increasingly occurs and develops over time. Activities in the Rampak Kendang community have been designed by trainers to match the actions of members who are mostly students of various levels. Renewal in the process of teaching the art of Rampak Kendang changes according to the desired output and is base on evaluation within a specified period. The assessment includes various aspects of both the regeneration process (input), the identity of the recess in the material substance (process) of the character formation (output) given. Thus the curriculum process that consists of individual components is made possible to enable curriculum development based on the evaluation of each part of the system itself [14].

The concept of non-formal education is different from formal education, which is defined as teaching in the form of instruction in learning in a structured and programmed way. Non-formal learning refers to consciously organized activities and motivated teaching in specific fields of knowledge, skills, or values, which occur outside the school or the same designated institution, with flexibility regarding age, instruction period, and with what choices to learn [15]. Thus, this nonformal education can serve the needs of various types of people, from farmers, women, dropping out of school, and who do not take formal education for various reasons, and can take advantage of formal education, either because they have passed the age for it or because they employed. This understanding can show the strengths of the Rampak Kendang community that has members of the elementary school-age community, junior high school age, senior secondary age, and even adults with age showing the flexibility of age. The researcher tries to relate to the nature of the curriculum, which is outlined as follows. The kind of the curriculum is divided into several, namely (1) curriculum as a plan, (2) curriculum as an experience, (3) curriculum as the subject, (4) curriculum as a goal, (5) curriculum as a system, (6) curriculum as field of study [15]. Based on this concept and related to the data on the object of research, it is found the nature of the curriculum of the art of Rampak Kendang shown in Table 1.

Table 1. The Nature of the Curriculum in the Art Community Rampak Kendang in Patimuan Cilacap, Indonesia

\begin{tabular}{|c|c|c|c|c|c|}
\hline Plan & Experience & Highlights & Objective & System & Field of Study \\
\hline $\begin{array}{c}\text { - Textual: } \\
\text { (aesthetic) } \\
\text { dance music, } \\
\text { infrastructure, } \\
\text { costumes, make } \\
\text { up. } \\
\text { - Contextual: } \\
\text { Honor for each } \\
\text { event, } \\
\text { Patimuanas } \\
\text { community } \\
\text { supporting } \\
\text { community. }\end{array}$ & $\begin{array}{c}\text { - Empirical } \\
\text { phenomena } \\
\text { from } \\
\text { community } \\
\text { leaders (agents) } \\
\text { and community } \\
\text { members. }\end{array}$ & $\begin{array}{c}\text { textual: } \\
\text { tone-originality } \\
\text { typical } \\
\text { Patimuan } \\
\text { Javanese } \\
\text { Sundanese. } \\
\text { - Material } \\
\text { Creativity and } \\
\text { technique of } \\
\text { playing music } \\
\text { and dance } \\
\text { movement } \\
\text { technique. }\end{array}$ & $\begin{array}{c}\text {-Results: } \\
\text { economics } \\
\text { - Process: art } \\
\text { (aesthetic, non- } \\
\text { aesthetic), } \\
\text { character education }\end{array}$ & $\begin{array}{l}\text { The first rules of } \\
\text { the chairman but } \\
\text { there is a mutual } \\
\text { agreement } \\
\text { (consensus), are } \\
\text { flexible following } \\
\text { the context of the } \\
\text { activity). }\end{array}$ & $\begin{array}{c}\text { Fields of study } \\
\text { include music } \\
\text { classes (focus } \\
\text { per-instrument), } \\
\text { and dance } \\
\text { classes. }\end{array}$ \\
\hline
\end{tabular}

Table 1 is a description of the nature of the curriculum contained in the learning of Rampak Kendang. The explanation includes the kind of the curriculum that is associated with the elements of 
the formation of a performance that emphasizes performance activities by not only looking at the meaning of the text in artistic activities and fused with the context as well [16]. The nature in the performance of Rampak Kendang in Patimuan in the form of rules from the chairman, but there is a mutual agreement or consensus (the system is more flexible and follows the context in each of the performance activities). This flexibility further emphasizes that the curriculum is very comprehensive in all spheres following the needs and interests of students. Rampak Kendang not only establishes themselves as a community but also accommodates the needs of the members who are still students. This is demonstrated by creating an educational environment, karma, procedures, and approaches that are appropriate for all members (students and non-students), and synergizing community members with their supporting communities. This is closely related to the members as individuals in social life. It also embodies an educational philosophy that aims to achieve value as the specific goals to be completed. Likewise, curriculum design in the Rampak Kendang community as a performance art has aesthetic (material) and non-aesthetic (non-material) functions.

The purpose of the curriculum can be maximized if it is supported by aspects of the experience of the teacher as an agent who transfers knowledge by linking the material with daily activities [17]. This integrative concept is following the learning process in the Rampak Kendang community, which is associated with daily activities in the city (closely related to art and economy) that can produce an output of character members. The integrative concept is not written down and is a hidden curriculum implementation in the Rampak Kendang art community. In line with the role of the trainer as a teacher, a study shows that art teachers use curricula, and responsive assessment and culture policies to enrich the nature of art education for students of various ethnicities in secondary schools [18]. This ensures that the Rampak Kendang community (community leaders and trainers have such an essential role as the control in managing the curriculum management created the community itself [19]. In his research revealed about the hidden curriculum, he told his own life experiences, which turned out there is also a curriculum that is unconscious, not detailed. Still, there is and provides solutions to problems in his life. Discussion of the curriculum begins with the design of the curriculum itself. Researchers call the plan a prototype. The prototype is the original type or form of something that serves as an example to make something new [20]. This is usually made to test the design before producing a new object. The original objective intended here is the hidden curriculum and also said that in the process of creating a curriculum, there needs to be the integration of art, creativity, and books. Then the researcher is interested in the elements of creativity and skill. Seeing how the community seems to be the drug in its activities is nothing but an artistic movement that will not be far from creativity.

One of the exciting things about the Rampak Kendang community is that there is a form of creativity through renewal and new appearance in the Rampak Kendang performance. Market tastes and involvement of members with student and teacher backgrounds (especially primary schools) bring about changes in the way materials are delivered and the desired outputs for their members. Creativity does not only come from the trainer but also arises from the role of members who provide new things during the training process to bring up new ideas in the Rampak Kendang presentation. Discovery-based learning in the creative process has indeed proven to be effective in producing desired outputs [21]. The findings or creativity developed in Rampak Kendang always follow the development of the times without leaving the original form of the unique Rampak Kendang performance. This is to maintain the values contained in the process of performing Rampak Kendang in it. Emphasis on the value of the process of art without leaving the nature of originality is an interpretation developed in eastern cultures [22]. Also, in his study, conveying the creativity of dance emerged by the coordination between dancers, choreographers, and performers [23]. This is in line with the development of dance in the Rampak Kendang community that can bring new creativity through the collaboration of the three elements above. Dancers (female community members and one male dance leader), there is the choreographer as an idea maker in the innovation of the dance movement (named Ratnaningsih), and the performers are all members of the dancers in the Rampak Kendang community. In the process of creativity, the members of the Rampak Kendang community formed a compound intelligence from each member of the community and gave rise to the characters in the learning process.

The results were reassured by Çubukçu who conveyed that character education is a planned and systematic approach in terms of respect, responsibility, and honesty, and others to become good citizens [24]. Hidden curriculum elements that are own in schools are values, beliefs, attitudes, and 
norms, and values that are an essential part of school functions, ceremonies, and the quality of interpersonal communication. This study aims to determine the supporting activities and views of students participating in these activities with the thought of expressing the importance of a hidden curriculum in obtaining character education in elementary schools.

Following the results of the above study, it is true that after the researchers also conducted observations, interviews, documentation found the character formed from various learning processes in art. Therefore, the hidden curriculum design of the Rampak Kendang art community is essential in being an example of the application of integrative concepts in the community art community. The plan was outlined in the form of a prototype to be easily understood and applied to other community art communities. The prototype/hidden curriculum design in the Rampak Kendang community illustrates the tactical steps in implementing hidden curriculums in art in the community. The characteristics of non-formal education that incorporate the concept of formal training in it can produce outputs, namely the formation of members' character through the sharpening of multiple intelligences in the process. The implementation of this hidden curriculum design is capable of producing different characteristics and multiple intelligences when applied to other community art communities in other regions. Based on the nature of the Rampak Kendang curriculum, and it is associated with the findings data in the Patimuan Rampak Kendang art community. Then described the design in the form of Prototype Hidden Curriculum Rampak Kendang Patimuan Cilacap in Figure 2.

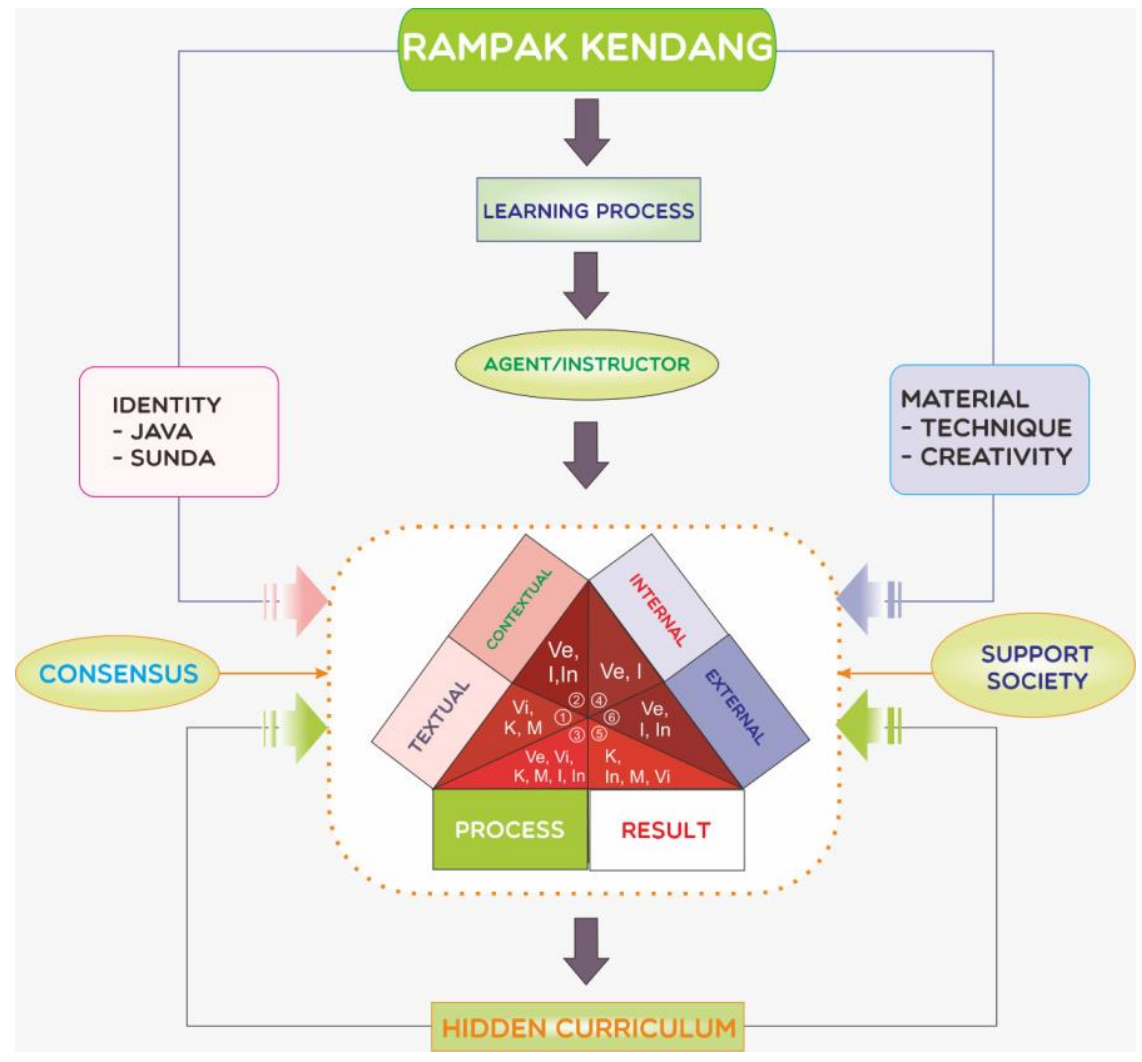

Fig. 2. Prototype Hidden Curriculum of Rampak Kendang Patimuan Cilacap, Indonesia.

Multiple intelligence information in the chart is Ve (Verbal), Vi (Visual-Spatial), $\mathrm{K}$ (Kinesthetic), M (Music), I (Interpersonal), In (Intrapersonal). While the description of the image is as follows. The process is a time course containing strategies during the training process. The results are the effects obtained after passing through the process of training by each member. Textual is all things related to the Rampak Kendang material. Contextual is everything that affects outside the Rampak Kendang material. Internal is everything that happens in the Rampak Kendang community. External is everything that happens outside the Rampak Kendang community. Figure 2 is a prototype of a hidden curriculum design that produces output in the form of multiple intelligences that are built up within members. The hidden curriculum can be formed through the support of 
various parties through a consensus between community leaders and their supporting communities, both residents and the local education office, which employs Rampak Kendang as one of the learning materials for students. This is also supported because of the emergence of new characteristics of the combination of the aspects of Central Java and West Java. Therefore, the material of the Rampak Kendang is increasingly interesting to be applied as SBdP material at the local elementary school. The involvement of members who are teachers and students more or less influences the members' processes and outputs in them. One thing that stands out is the development of multiple intelligence processes in the art process of its members. The prototype above shows that multiple intelligence appears in the slices of the activity of the art of Rampak Kendang. The slices of these activities are (1) in the process activities, internal and textual can develop unique visual, kinesthetic, and musical bases. (2) contextual, process, the domestic business produces verbal, intrapersonal, and interpersonal intelligence. (3) textual activities, processes, produce oral, visual special, kinesthetic, music, and interpersonal intelligence. (4) contextual, result, external events provide verbal, intrapersonal, and interpersonal information. (5) the textual, achievement and external activities produce kinesthetic, intrapersonal, musical, and visual-spatial intelligence, and (6) contextual, internal, and result activities provide verbal knowledge and interpersonal.

Outputs that emphasize this aspect of intellectual development can be formed if there is an involvement of educational elements in it. These elements include members who are teachers and students, the role of dance choreographers as one of the primary school teachers, and the involvement of the Rampak Kendang art community in school activities both in the curriculum as one of the SBdP materials and representing local education offices in regional-scale events. The integration of values in non-formal education and character formation in the concept of formal education can produce multiple intelligence in the hidden curriculum process in teaching.

\section{Conclusion}

The hidden curriculum of the art community of Rampak Kendang Patimuan is a curriculum in the form of activities carried out unwritten, which can produce outputs of the character formation of its members. The hidden curriculum can work well if it is supported by consensus and support from the local community. The invisible curriculum design of the Rampak Kendang community is different. It deserves to be used as a reference in the implementation of inputs, processes, and outputs in running the arts community in the city. The involvement of the subject and the concept of formal education in the activities of the Rampak Kendang can bring up new colors which impact on the development of multiple intelligence members. This kind of idea needs to be developed to produce outputs of members of the community artists who are not only able to demonstrate expertise in textual (artistic), but also character through the process of developing multiple intelligence during the process of art. The activities of the Rampak Kendang community in this educational institution also show a real integration between the concept of formal education in non-formal education or vice versa.

\section{Acknowledgment}

This research was funded by the Directorate of research and Community Service, The Ministry of Research, Technology, and Higher Education, following the Research Grant Agreement Letter number: PKPT-065 / SKPP / III / 2018. The researchers say thank you for Ahmad Dahlan University as our home base, Gadjah Mada University, as associated researcher team's Homebase and LPPM which is facilitated us to go through with this research. We would also like to express our gratitude to the Rampak Kendang community under the command of Riswanto in subdistrict Patimun Cilacap that gives us time and opportunity to find out more about the processes and activities of Rampak kendang community.

\section{References}

[1] B. G. Massialas, "Hidden Curriculum in the Classroom," in International Encyclopedia of the Social \& Behavioral Sciences, 2001, pp. 6683-6685.

[2] T. McCowan, G. Janmaat, and N. Rao, "Community, curriculum and learning," Compare, vol. 46, no. 3, pp. 341-343, 2016. 
[3] Widodo, "Tari Kendang Rampak Meriahkan Pembukaaan Popdaseni Cilacap," tabloidpamor.com, 2017. [Online]. Available: https://tabloidpamor.com/index-2.php?view=news\&tari-kendang-rampakmeriahkan-pembukaaan-popdaseni-cilacap\&PMR=VG5wak5RPT0=.

[4] B. Nel, "The Demise of Traditional Performance Management Systems," Perform. Improv., vol. 55, no. 3, pp. 10-12, 2016.

[5] B. S. Carpenter, "Community Art Curriculum," in The International Encyclopedia of Art and Design Education, 2019, pp. 1-12.

[6] C. R. Garoian, "Performance and the Event of Art Curriculum," in The International Encyclopedia of Art and Design Education, 2019, pp. 1-7.

[7] N. K. Denzim and L. Y. S., Handbook of Qualitative Research. Yogyakarta: Pustaka Pelajar, 2009.

[8] M. B. Miles, A. M. Huberman, M. A. Huberman, and M. Huberman, Qualitative Data Analysis: An Expanded Sourcebook. sage, 1994.

[9] O. Albert I, Curriculum Improvement. New York: Dodd mead and Co, 1977.

[10]H. Taba, Curriculum: Theory and Practice. New York: Harcourt, Brace, 1962.

[11]R. Boyd and P. J. Richerson, Culture and the Evolutionary Process. University of Chicago press, 1988.

[12]M. Ebrahimi, B. Majidi, and M. Eshghi, "Procedural Composition of Traditional Persian Music Using Deep Neural Networks," in 2019 IEEE 5th Conference on Knowledge Based Engineering and Innovation, KBEI 2019, 2019, pp. 521-525.

[13] J. McDonald, "Australia's rock art heritage: A thematic approach to assessing scientific value," in The Oxford Handbook of the Archaeology and Anthropology of Rock Art, 2017, pp. 197-220.

[14] A. D. M. Lalor, Ensuring High-Quality Curriculum: How to Design, Revise, or Adopt Curriculum Aligned to Student Success. ASCD, 2016.

[15] A. Tholappan, Knowledge and Curriculum, 2015th-2016th ed. India: Bharathidaan University, 2015.

[16]L. Simatupang, Pergelaran (sebuah mozaik penelitian seni-budaya). Yogyakarta: JALASUTRA, 2013.

[17] Saide, Curriculum. Afrika: Oxford university press, 2009.

[18]J. Smith, "Curriculum, Assessment and Pedagogy: How These Dimensions are Enriching Visual Arts Education for Ethnically Diverse Students in New Zealand Secondary Schools," J. Educ. Cult. Stud., vol. 3, no. 3, p. p311, 2019.

[19] J. Hariharan, “Uncovering the hidden curriculum,” Science, vol. 364, no. 6441. p. 702, 2019.

[20] K. T. Ulrich, ABC (art, books, creativity) Art Learning and classroom-. National Museum of Woman In the Arts, 2010.

[21]R. Y. K. Lau, "Discovery-Enriched curriculum: A text mining approach for assessing students' discoveries," in Ubi-Media 2017 - Proceedings of the 10th International Conference on Ubi-Media Computing and Workshops with the 4th International Workshop on Advanced E-Learning and the 1st International Workshop on Multimedia and IoT: Networks, Systems and Applications, 2017.

[22] H. H. Kim, S. Mishra, P. Hinds, and L. Liu, "Creativity and culture: State of the art," in Design Thinking Research: Studying Co-Creation in Practice, 2012, pp. 75-85.

[23] P. Thomson, "Dance and Creativity," in Encyclopedia of Creativity, 2011, pp. 343-350.

[24]Z. Çubukçu, "The effect of hidden curriculum on character education process of primary school students," Kuram ve Uygulamada Egit. Bilim., vol. 12, no. 2, pp. 1526-1534, 2012. 